\title{
Infancia mapuche encerrada: internados de las escuelas-misiones en la Araucanía, Chile (1900-1935)*
}

\author{
Juan Guillermo Mansilla Sepúlveda' \\ Claudia Andrea Huaiquián Billeke' \\ Gabriel Alfonso de Dios Pozo Menares"
}

\section{RESUMEN}

Este artículo estudia el funcionamiento de internados de niños y niñas en el territorio de la Araucanía administrado por misioneros capuchinos, entre 1900 y 1935, periodo en el cual se consolidó la política reduccional del pueblo mapuche ejercida desde el Estado de Chile. El método fue cualitativo-descriptivo con un diseño historiográfico, el cual a partir de la triangulación metodológica permitió encontrar las siguientes categorías: choque cultural chilenización/evangelización/mundo mapuche en el internado, infancia mapuche encerrada según género, infancia mapuche reglamentada: formalización de rutinas, visitas controladas internados por parte de familias, justificación ideológica/presencia del internado; pérdida del mapuzungun y, agentes de la vigilancia y el control. Los resultados pueden contribuir a promover el interés por estudiar un campo inexplorado por la investigación educativa en América Latina: rol pedagógico de los internados en contextos de relaciones interétnicas.

\section{PALABRAS CLAVE}

internados; valores culturales; infancia mapuche; escuela misión; vigilancia y control.

\footnotetext{
*Este artículo se ha desarrollado en el contexto del Proyecto CONICYT/ FONDECYT Regular n. 1160409. 'Universidad Católica de Temuco, Temuco, Chile.

"Universidad Católica de la Santísima Concepción, Concepción, Chile.
} 


\title{
MAPUCHE CHILDHOOD LOCKED UP: INTERNSHIPS OF SCHOOLS-MISSIONS IN LA ARAUCANIA, CHILE (1900-1935)
}

\begin{abstract}
This article studies the operation of boarding schools for children in the territory of Araucanía, administered by Capuchin missionaries, between 1900 and 1935, during which the reduction policy of the Mapuche people was consolidated in Chile. The method was qualitative-descriptive with a historiographic design, from which, the following categories were found by a methodological triangulation: cultural shock Chileanization/evangelization/Mapuche world in the boarding school, Mapuche childhood separated according to gender, regulated Mapuche childhood: formalization of routines , controlled visits to the internees by their families, ideological justification/presence of the boarding school; Loss of the mapuzungun (Mapuche Language), agents of surveillance and control. The results can contribute to promote interest in studying an unexplored field of educational research in Latin America: the pedagogical role of internees in contexts of interethnic relations.
\end{abstract}

\section{KEYWORDS}

internships; cultural values; mapuche childhood; schools-missions; monitoring and control.

\section{INFÂNCIA MAPUCHE ENCARCERADA: INTERNOS DE ESCOLAS-MISSÕES NA ARAUCÂNIA, CHILE (1900-1935)}

\section{RESUMO}

Este artigo examina o funcionamento de internatos para crianças no território de Araucânia, Chile, administrados por missionários capuchinhos entre 1900 e 1935, período no qual se consolidou a política reducional do povo Mapuche exercida pelo Estado do Chile. A metodologia de pesquisa utilizada foi a qualitativa descritiva, com delineamento historiográfico, que a partir da triangulação metodológica permitiu encontrar as seguintes categorias: choque de culturas chinelização/evangelização/mundo Mapuche em internato; crianças Mapuche separadas por gênero; infância Mapuche regulamentada com a formalização de rotinas e visitas controladas aos internatos para as famílias; a justificação ideológica/presença do internato; perda do mapudungun, idioma Mapuche; e agentes de vigilância e controle. Os resultados podem ajudar a promover o interesse em estudar um campo inexplorado de pesquisa educacional na América Latina: o papel pedagógico das escolas em sistema de internato em contextos de relações interétnicas.

internato; valores culturais; infância Mapuche; escolas-missões; monitoramento e controle. 


\section{INTRODUCCIÓN}

En Chile, al norte del río Biobío, las condiciones post independencia estaban dadas para su ejercicio real, mientras que al sur del mismo río la soberanía era nominal ya que aun pervivía la vieja frontera colonial. Existía una herencia institucional, pero autónoma del Estado central chileno y vinculada muy frágilmente a su aparato burocrático, por lo que fue necesario activarla y volverla funcional al gobierno estatal. Al norte de la Araucanía presentaba un orden distinto del institucional central. El principal pensador y promotor de esta idea fue el multiministro Antonio Varas de la Barra (1817-1886), quien planificó diversas estrategias para incorporar la Araucanía a Chile. La educación aparece como una de las apuestas más complejas y fundamentales para lograr tal cometido. Para concretar este propósito el rol complementario que proporcionaba la iglesia católica sería fundamental, especialmente a través de los agentes misioneros, principalmente franciscanos, capuchinos y salesianos.

Entonces, "el objeto principal de donde el misionero debe esperar más, y al que debe dirigir sus miras es la educación, e instrucción de los niños indígenas" (Palavicino, 1860, p. 56-57). Las ideas de Varas no fueron completamente implementadas, pero algunas misiones - como las capuchinas - incorporaron en la entrega de las primeras letras, la práctica de algunos oficios menores (Guevara, 1904). La tarea de las misiones sería, entonces, "civilizar" mediante la conversión a los mapuches, pues si no se modificaban las creencias no se cambiaban las conductas y, sin esta transformación, la civilización no es más que una 'quimera'. En este sentido, la escuela chilena como agencia, de la cual forma parte el internado, no ha sido un espacio de desarrollo personal y reafirmación identitaria para niños y niñas mapuche de zonas rurales. Una de las razones puede ser que la escuela no ha desarrollado un curriculum culturalmente situado que permita una construcción desde los propios indígenas, émicamente (Geertz, 1973).

El objetivo de la presente investigación es develar descriptivamente el funcionamiento de internados de niños y niñas en el territorio de la Araucanía administrado por los misioneros capuchinos, entre 1900 y 1935, periodo en el cual se consolidó la política reduccional del pueblo mapuche ejercida desde el Estado de Chile. Entonces, es pertinente preguntarse ¿Cómo el Estado de Chile logró inmediatamente después de la ocupación del territorio mapuche denominado Araucanía (1881-1883) crear un grupo de agentes, principalmente profesores, consolidar un sistema que declaraba chilenizar, evangelizar y civilizar a los indígenas mapuches? Teniendo en cuenta esta pregunta orientadora, la investigación se propone estudiar algunas dimensiones del proceso de instalación de internados que funcionaban anexos a las escuelas misionales, al mismo tiempo que se asentaba el sistema de instrucción pública y se creaban escuelas particulares para atender a los inmigrantes alemanes, suizos, franceses, españoles e italianos, principalmente.

Debemos recordar que el Estado de Chile entre 1833 (Primera Constitución de la República) y 1925 (Segunda Constitución) no estuvo separado de la Iglesia Católica, lo que facilitó la presencia activa de diversas congregaciones religiosas. Fue así como en 1848 el Gobierno de Chile les solicitó a los capuchinos italia- 
nos para que ayudaran a los padres franciscanos en sus correrías evangelizadoras y civilizadoras. Se hicieron cargo de todas las misiones ubicadas entre los ríos Cautín y Maipué. Los misioneros capuchinos italianos fundaron: 1. Bajo Imperial (Puerto Saavedra), 1850; 2. Queule, 1854; 3. Convento de Concepción, 1855; 4. Toltén, 1860; 5. Rahue, 1863; 6. Purulón, 1874; 7. Boroa, 1883, y; 8. Villarrica, 1899 (Witt, 1963). En 1895 habiéndose reducido el personal de los padres italianos a 10 misioneros, llegaron desde Múnich — en auxilio de ellos -, los capuchinos de Baviera, que trabajaron bajo las órdenes del Prefecto Italiano hasta 1900, año en que la Prefectura de la Araucanía pasó definitivamente a manos de los capuchinos bávaros (Hoffmann et al., 2006). Figuraron entre los primeros capuchinos bávaros los RR.PP. [Reverendos Padres] Félix de Augusta, Tadeo de Wisent y el hermano Fray Sérvulo de Gottmannshoffen. A los pocos meses, a fines de 1896, llega el segundo grupo de padres capuchinos, destacándose Atanasio Hollermayer y Sigisfredo de Frauenhäusl (Gunckel, 1945).

Bajo el nuevo Prefecto R.P. Bucardo María de Rottingen (1900-1925) se efectúo la división territorial de la jurisdicción del Obispado de Ancud y la Prefectura Apostólica de la Araucanía. En este contexto aparece como dispositivo de control de los mapuches la triada escuela, misión, internado, constituyéndose en un efectivo, sutil y violento dispositivo de control y poder que permitió a los misioneros católicos complementar el proceso de ocupación de la Araucanía iniciado por el Estado de Chile. El campo de trabajo encomendado a los capuchinos bávaros con el nombramiento de un Prefecto de su propia nacionalidad, comprendía en aquel tiempo el territorio que limitaba por el norte con el río Cautín y por el sur el río Maipué (Noggler, 1972).

En este escenario hubo diversos dispositivos de poder y control que se aplicaron en el territorio mapuche: comercio post-fronterizo y refundación de ciudades, evangelización católica y protestante, acción militar directa, parlamentos, escuelas laicas y misionales e internados. Por tanto, interesa estudiar una de las instituciones menos investigadas en Chile y América Latina: los internados.

El internado concebido como hogar-familia, fue un planteamiento intermedio entre las tradiciones pedagógicas del siglo XIX y los postulados de la escuela nueva, que resultó práctico en un contexto de escasos recursos y desconfianza de la escuela mixta (Civera Cerecedo, 2006, p. 58). Los inicios de los internados en América Latina tuvieron diferentes denominaciones: hogares de menores; hospicios para pobres; asilos; internados parroquiales, internados indígenas, casas de indígenas. Fueron extremadamente modestos y estaban constituidos por salones y piezas equipadas con el mobiliario básico y útiles estrictamente necesarios (Muriá y Olveda, 1992, p. 256). En los colegios misionales con internado, los capuchinos tuvieron como norma general que nunca se dejase a los niños sin vigilancia y que los misioneros "los trataran con mucho cariño" para que durante toda su vida guardara un buen recuerdo de la misión (Noggler, 1972, p. 145).

En el caso de los internos, cada ocho días escogían "democráticamente" a un jefe, quien también tenía la obligación de informar todos los días sobre el comportamiento de los compañeros en el desempeño de sus trabajos. El reglamento interno disponía que los maestros debían cuidar la disciplina por turnos semanales, funcionando como inspectores. 
En el centro de la Figura 1 se visualizan dos círculos concéntricos. La superficie del mayor representa la totalidad de los habitantes del territorio del Vicariato apostólico de la Araucanía. La menor parte corresponde a los niños de ambos sexos que tienen la obligación de asistir a la escuela. El sector negro del círculo refleja el porcentaje de niños que frecuentaba las escuelas misionales católicas del Vicariato. El otro más gris, son estudiantes que recibían su educación en la misión anglicana de Quepe. Ambos sectores abarcan casi el mismo número, que el sector más claro, representado por los niños que asisten a colegios fiscales. El sector en blanco da una idea del número de niños que aún no recibían instrucción en 1935. En este esquema, hay tres fajas dobles y una simple. La primera, la más pequeña, representa la matricula total de los internados que sostiene el Vicariato Apostólico de la Araucanía, que ascendía a 1300. Una línea horizontal divide esta franja en dos partes: el número de niños (abajo) y el número de niñas (arriba). La parte derecha de la faja, indistintamente del género del estudiante, representa la proporción de niños, mestizos y mapuches. La base del rectángulo indica datos que van desde 1900 a 1935. En la esquina opuesta, el diagrama de matrícula del rectángulo, se visualiza otro diagrama que refleja el aumento de la matrícula y de los edificios escolares, propiedad de los misioneros o arrendatarios. Así, en 1900 había seis escuelas misionales, representadas por los seis cubos. En 1920, ya eran 24; en 1925, 37; en 1930, 63. Y en 1935, los 7.180 escolares asistían a 106 escuelas y 22 internados (Fondo de Intendencia De Cautín, 1931).

En síntesis, escuelas e internados se transformaron en un espacio social de encuentro/desencuentro entre el saber prescriptivo de los grupos hegemónicos del

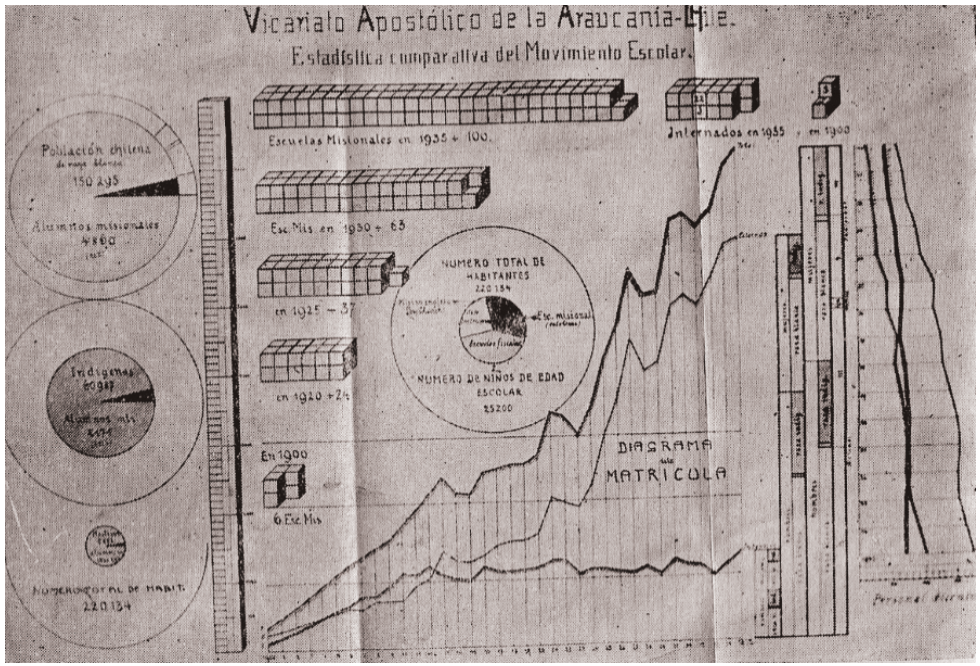

Figura 1 - Diagrama original de matrícula estudiantil Vicariato Apostólico de la Araucanía 1935.

Fuente: Vicariato Apostólico de la Araucanía, 1925. 
Chile central, y aquellos saberes locales de la sociedad mapuche, especialmente respecto a los niños que vivieron su escolarización "internos", que a fines del siglo XIX fueron una cantidad reducida, preferentemente hijos de longkos [principales dirigentes de las comunidades]. Este ingreso de los mapuches al diagrama disciplinario de la escuela occidental a través del dispositivo internado fue aumentando conforme avanzaron los decenios. La invisibilización de los saberes mapuches se manifiesta especialmente en el bloqueo del uso de la lengua materna, pues el idioma con el cual se enseñó los contenidos en sectores con una alta densidad de población indígena fue el castellano (Sepúlveda et al., 2016).

\section{MARCO TEÓRICO}

\section{EL INTERNADO COMO INSTITUCIÓN TOTAL}

Los internados pueden considerarse instituciones totales, donde un gran número de individuos en igual situación, aislados de la sociedad por un periodo apreciable de tiempo, comparten en su encierro una rutina diaria, administrada formalmente (Goffman, 1972, p. 13). En el internado todos los aspectos de la vida se desarrollan en el mismo lugar y bajo una autoridad única. Cada etapa de la actividad diaria del interno o interna se lleva a cabo en la compañía inmediata de un gran número de otros, en que todas las actividades diarias están estrictamente programadas. La vigilancia y el control son mecanismos eficientes y muy importantes: ver que todos hagan lo que se ha dicho claramente que se exige de ellos, en condiciones que la sanción de un individuo probablemente se destacaría en singular relieve contra el fondo de sometimiento general, visible y comprobado (Goffman, 1972, p. 20). Los estudiantes internos desarrollan su mundo de la vida dentro de la institución y tienen limitados contactos con el mundo de los estudiantes externos. Por consiguiente, las relaciones intersubjetivas se desarrollan entre los agentes de control: directores, inspectores administrativos, misioneros, religiosas, y auxiliares. Es una relación asimétrica de micropoder, visualizándose gran distancia social entre los agentes. La conversación misma entre un grupo a otro devela sometimiento y se produce a través de un tono especial de voz (Goffman, 1972, p. 21).

El modelo de los internados exige extensos periodos de permanencia y encierro generando efectos complejos para la infancia de quienes se encuentran en esta condición: desvinculación afectiva de la familia de origen y de esta respecto a sus hijos; hábitos adquiridos en disonancia con el mundo de la vida desde donde provienen; configuración de una identidad que se traduce en una 'persona débil' en habilidades sociales (Domínguez, 2009). En este sentido, las escuelas y los internados se constituyen en eficientes dispositivos para crear y recrear de modo sistemático la comunidad imaginada (Anderson, 1993). Su ideario fue de naturaleza ideológica: enseñar las primeras letras del idioma dominante en espacios subnacionales (Flores, 2010); enseñar al pueblo (Amunátegui y Amunátegui, 1856); y por sobre todo, civilizar al indígena (González, 2002). La escuela, misión e internado surgen 
en un contexto marcado por el positivismo, el cual implicaba, de manera simultánea, una teoría de la ciencia y una reforma de la sociedad, es decir, la ciencia y sus aplicaciones van constituyendo la sociedad para organizar la vida de las personas, destacándose como principios basales el orden como base y el progreso como fin. Esto adquirió especial relevancia a fines del siglo XIX en diferentes países latinoamericanos (Solana et al., 2014).

El contacto cotidiano con los pares (otros internos) se realiza a través de un sistema creativo de apodos, sobrenombres o diminutivos, constituyéndose esta práctica en un sutil modo de violencia simbólica (Bourdieu, 2007). Asistimos, así, a una pérdida de autodeterminación. Son los reglamentos los que indican el tiempo para bañarse, comer y la paz nocturna para dormir. En razón de esto se explica que la conversación entre los internos gira de ordinario en torno a fantasías de liberación, o sea, planes sobre los que cada uno se propone hacer con la primera licencia que tenga, el plan siempre es el mismo: huir del internado (Goffman, 1972, p. 60). Sin embargo, frente a estos procesos, un elemento característico es la tendencia a la solidaridad manifestada en la fraternización y en la conformación de amigos.

\section{EFECTOS DE LA ESCUELA-MISIÓN-INTERNADO}

El proceso de monoculturización y colonización del alma y cuerpo de los estudiantes internos se produce a través de tres situaciones:

1. Línea de la regresión situacional. Los estudiantes internos retiran su atención aparente de todo cuanto no sean los hechos inmediatamente referidos a su cuerpo, se produce una abstención drástica de la participación social activa extra muro de los internados;

2. Línea intransigente. Los estudiantes internos se enfrentan con la institución en un deliberado desafío y se niega abiertamente a cooperar con los reglamentos. En este contexto se produce un efecto contrario, ya que la institución comienza a focalizar a los indisciplinados o indisciplinadas, y la institución muestra un interés tan apasionadamente por el rebelde, como el que éste mostró hacia ella; y,

3. Colonización. Se produce una progresiva valoración del mundo del internado. La acomodación al mundo del internado podría reflejar la idea de "haber encontrado un hogar", en tanto desde los guardianes de la institucionalidad del internado surge la percepción de un aprovechamiento de la institución, un abuso de las posibilidades benéficas que la situación ofrece (Goffman, 1972, p. 71).

Es menester aclarar que habitualmente quienes ingresan a un internado generalmente no lo hacen por voluntad propia. "Los allí recluidos no pueden disponer de su propio tiempo; las citas y rutinas están prefijadas; no existe esfera privada; siempre aislados, pero nunca solos; son comunes las humillaciones rituales y pérdida de realidad condicionada por el sistema, esto aumentaba la duración de la estancia" (Bueno, 1996, p. 65). Otro aspecto importante que se debe considerar es 
el financiamiento de los internados. Las fuentes de los subsidios que permitieron el desarrollo de los internados fueron los siguientes agentes:

1. Gobierno de Chile. Que en estricto rigor fue el ente que llamó a los padres capuchinos para el desenvolvimiento e implementación de la misión en la Araucanía. Este aporte fue decreciendo a partir de 1881, porque el Estado de Chile focalizó los dineros para ejército de ocupación;

2. Sociedad Protectora de Indigenas. Institución fundada por Isabel Correa de Irarrázabal. Donó por mucho tiempo generosas sumas de dinero. Organizó fiestas literarias para reunir fondos; Obra de Propagación de la $\mathrm{Fe}^{1}$. Institución que por instrucción del Papa, entregaba a los internados administrado por misioneros y religiosas parte del dinero recolectado; Gente Católica de Baviera. Estos aportes eran muy valorados por los misioneros y lo subrayaban, sobre todo en el periodo de entreguerras (1919-1939), pues se desprendía de todo lo que tenían (Vicariato Apostólico de la Araucanía, 1966).

Los principales internados femeninos eran administrados por la Hermanas Maestras de la Santa Cruz en la primera mitad del siglo XX y no eran gratuitos. Se pagaba una pensión que variaba según la época en que ingresaban. La pensión anual era de $\$ 900$, cuyo pago se distribuía de la siguiente forma: al ingresar la alumna al colegio, $\$ 300$; en la primera quincena de junio, $\$ 300$; y en la primera quincena de septiembre, $\$ 300$ (Religiosas Maestras de la Santa Cruz, 1912, p. 6-7).

$\mathrm{El}$ trasfondo de este proceso se vincula con la educación indígena, en tanto mecanismos de control social y dispositivo ideológico para lograr la "salvación" de los mapuches y así fortalecer la inculturación (Pereira Contardo, 2002, p. 11). Los "colegiales" provenían de los cuatro butalmapus ${ }^{2}$ de la tierra al sur del Biobío con consentimiento de sus padres mediante influjos y oportunas persuasiones que en las ocasiones de juntas y visitas con el maestro de campo se les hacen de las ventajas que lograrán de ser educados a cargo de los españoles. La edad de ingreso se situaba entre los 10 y 12 años (Pinto Rodríguez, 1988).

Todos los niños que vivían en el territorio chileno, indistintamente de su condición cultural, debían amar a la patria para así sedimentar el proyecto político de los grupos dirigentes del Estado de Chile. La idea de nación y de Estado-nación de la centuria decimonónica en Chile ha sido formada por un Estado que ha antecedido a ella, a semejanza, en esto, de la Argentina; y a diferencia de México y el Perú, donde grandes culturas autóctonas prefiguraron los Virreinatos y las Repúblicas (Góngora, 1981).

1 La Obra de la Propagación de la Fe tenía como propósito fundamental la formación del clero indígena.

2 Butalmapus o fütalmapu: expresión mapuche donde füta es "gran” y mapu: "tierra" o "territorio". Son cuatro los butalmapus: la costa (Lafkenmapu), los llanos (Lelfünmapu), la precordillera de los Andes (Inapiremapu) y la cordillera (Piremapu) (Wilhelm de Moesbach, 1959, p. 115). 


\section{MÉTODO}

La metodología corresponde a un diseño cualitativo descriptivo-denso buscando la comprensión de los fenómenos (Taylor y Bogdan, 1984; Flick, 2004; Geertz, 2003) a partir de un diseño historiográfico donde lo que se pretende es comprender los hechos, más que juzgarlos a partir de la evidencia de los documentos (Ginzburg, 1997; Hartog, 2011). La investigación se desarrolló en tres etapas. En la primera fase se sistematizó el fichaje de fuentes primarias, lo que permitió la elaboración de un corpus documental-base para realizar los análisis posteriores. La segunda fase significó levantar un marco teórico que permitió realizar triangulaciones entre fuentes primarias y fuentes secundarias. Y en la tercera fase, se realizaron entrevistas narrativas (Flick, 2004) y dialógicas (Ferrada et al., 2015) que permitieron obtener datos densos sobre las vivencias, alegrías, sufrimientos, emociones, relaciones interpersonales recordadas por personas mapuche que vivieron en internados. Estas entrevistas se realizaron bajo la lógica mapuche de conversación denominada nütram (conversación en torno al mate, el fuego y la comida). Estos relatos también actualizaron reminiscencias de sus padres y abuelos que conocieron la experiencia de "estar internos" en escuelas misionales. Y la cuarta fase, consistió en el levantamiento de categorías a partir de la triangulación entre las notas escritas y orales.

El trabajo de campo implicó revisión y análisis de fuentes primarias en fondos documentales del Archivo Nacional de Chile, Archivo Regional de la Araucanía (Temuco), Biblioteca Nacional de Chile (Santiago) y Biblioteca Galo Sepúlveda (Temuco), Archivo de las Hermanas Misioneras Franciscanas de Purulón, Archivo de las Hermanas Maestras de la Santa Cruz, Archivo del Obispado de Villarrica, Archivo Fotográfico de la Katholische Universität Eichstätt-Ingolstadt y el Archivo de la Abadía de los Capuchinos en Altötting "Santa Magdalena", estos últimos en Baviera, Alemania. La microfilmación de diversos fondos documentales incluyó decretos de los fondos de la Intendencia de Cautín y gobernaciones del periodo estudiado, comunicaciones recibidas, oficios despachados, telegramas e informes, libros, epistolarios. Asimismo, se revisó literatura especializada respecto de la relación entre enseñanza monocultural, mundo mapuche e instalación del Estado de Chile en la Frontera.

\section{RESULTADOS}

A partir de la triangulación de las fuentes se levantaron siete categorías:

1. choque cultural chilenización/evangelización/mundo mapuche en el internado;

2. infancia mapuche encerrada y separada según género;

3. infancia mapuche reglamentada: formalización de rutinas;

4. visitas controladas a los internados de parte de las familias;

5 justificación ideológica de la presencia del internado;

6. pérdida del idioma mapuzungun y alteración del mogen 3 ;

7. agentes de la vigilancia y control.

3 Mogen: expresión mapuche que alude al modo de estar y ser en el mundo (Noggler, 1972). 


\section{CATEGORÍA 1. CHOQUE CULTURAL CHILENIZACIÓN/EVANGELIZACIÓN/MUNDO} MAPUCHE EN EL INTERNADO

En diversos lugares de la Araucanía donde existía una densa presencia de población mapuche se erigieron escuelas misiones y de modo anexo internados. Se encontró que en San José de la Mariquina (actualmente comuna perteneciente a la provincia de Valdivia en el extremo noroeste de la región de los Ríos) el misionero bávaro R.P.Mamerto fue el primero en levantar el 1º de marzo de 1904 una escuela, y junto a la escuela, una modesta casa que servía de internado, espacio donde él también vivía. Este sacerdote capuchino compró trescientos pesos de género para vestir a los niños mapuches al modo "occidental-chileno", y un "molinillo" para preparar su alimento "primitivo": la harina tostada (Noggler, 1972, p. 150). Así se visualiza en el siguiente texto:

(...) En la amistad y las relaciones que tengo con los indios que viven más al interior, habría podido conseguir muchos niños internos y establecer una misión importante. Pero por falta de un compañero, no puede hacerse más y por eso siguen en las tinieblas del paganismo (...) (De Pamplona, 1911, p. 98)

La traducción del reverso de esta fotografía dice Das neue Knabenkolleg von Boroa, gebaut 1918/19, Raum für 100 Indian.Knaben, bezogen April 1919. Bd. 1, S. 102 , unten, lo que se traduce como "El nuevo colegio de niños de Boroa, construido 1918/19 con espacio para 100 niños indios, ocupado/habitado abril 1919. Tomo I,

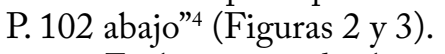

En los internados las prácticas religiosas eran variadas según el celo e ideas de los misioneros, tanto anglicanos como franciscanos o capuchinos. Algunos tenían "un modo más riguroso de juzgar cuántas veces los niños debían comulgar a la semana” (Noggler, 1972, p. 161).

\section{CATEGORÍA 2. INFANCIA MAPUCHE ENCERRADA Y SEPARADA SEGÚN GÉNERO}

Cuando una persona va a dejar a su hijo o hija a un internado se transforma en un "depositante". Entre los motivos que se destacan para recluir a niñas a fines del siglo XIX en el sur de Chile y Argentina puede mencionarse, además del interés por su formación cristiana y adiestramiento como futura ama de casas, la preservación de la pureza sexual. Algunas de estas niñas, sobre todo en los internados urbanos salían de esta institución solo al momento de casarse y otras pasaban de la escuelamisión-internado directamente a tomar los hábitos como monjas en algunas de las casas existentes en el sur de Chile (Ghirardi y Vassallo, 2010, p. 95). El sistema de reclusión femenina en colegios poco tenía que ver con la instrucción, lo más atrayente consistía para las familias, en que permitía evitar los vicios de la educación doméstica, donde dormían demasiado y se mantenían ociosas y más expuestas a las rebeliones de la carne (Nizza da Silva, 1999, p. 29). En la Araucanía la formación

4 Traducción realizada por la historiadora alemana Johanna Umbach, quien participa como investigadora del Proyecto FONDECYT regular n. 1160409. 
de las alumnas internas desde principios del siglo XX estuvo a cargo de diversas congregaciones religiosas femeninas, principalmente las religiosas de la Santa Cruz, religiosas Franciscanas y religiosas de la Providencia. Uno de los aspectos más interesantes de la formación que identificó las prácticas formativas es el control de todos los aspectos del mundo de la vida cotidiana de las alumnas internas: desde

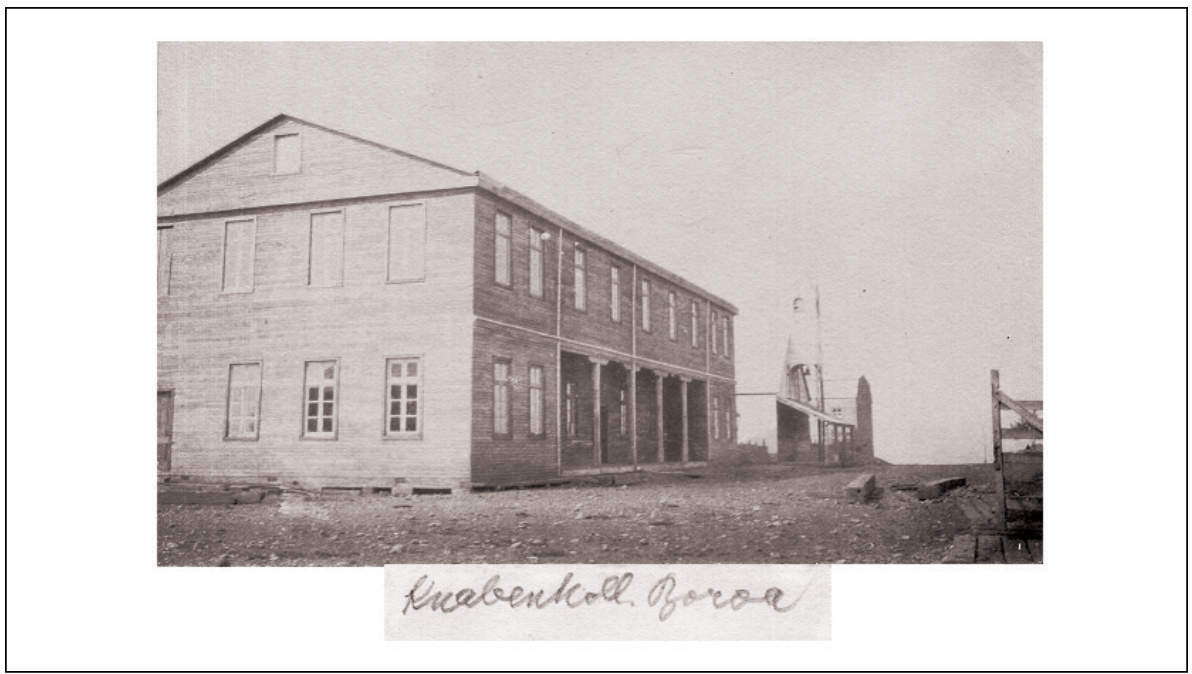

Figura 2-Anverso fotografía. Colegio de Niños.

Fuente: Álbum 2 (Seite II). Archivo Capuchino de Altötting (Archiv Der Bayer-Kapuzinerprovinz, Universitat EichstaettIngolstadt, 1919).

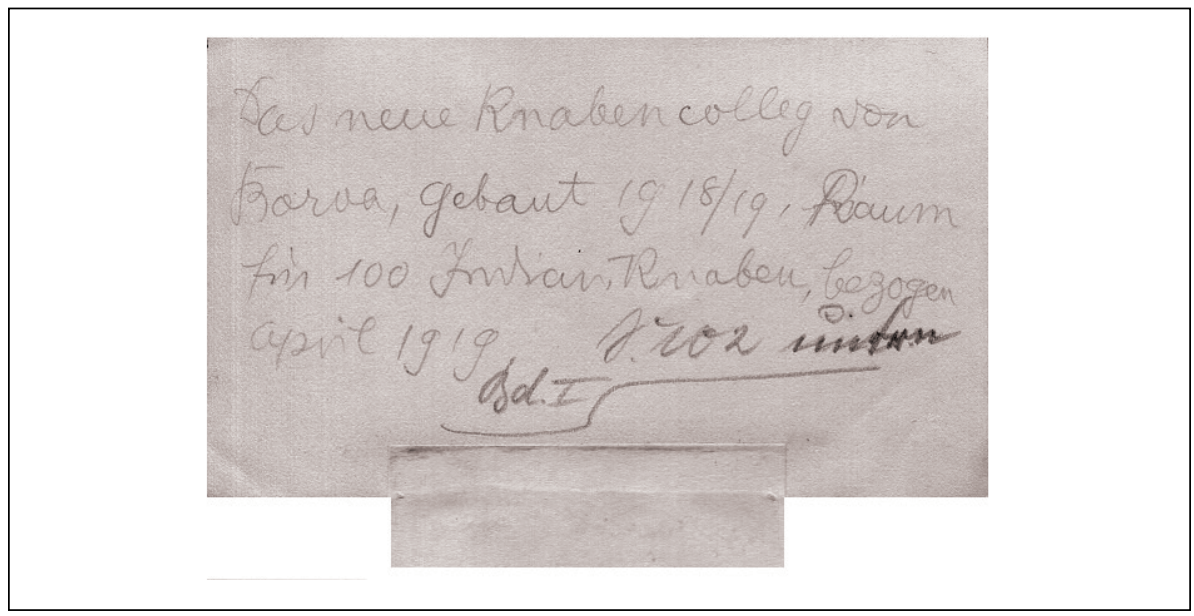

Figura 3 - Escritura en el reverso fotografía. de Boroa, 1919.

Fuente: Álbum 2 (Seite II). Archivo Capuchino de Altötting (Archiv Der Bayer-Kapuzinerprovinz, Universitat EichstaettIngolstadt, 1919). 
el aseo y modo de vestirse hasta lo que debían hacer y no hacer, cuando se debían despertar y a qué hora cerrar los ojos para dormir. En este sentido, particularmente interesante resulta reconstruir la prolijidad, disciplinamiento del cuerpo y vigilancia para que los reglamentos se cumplan, por ejemplo, con el ajuar que debían traer consigo en el momento que logran la condición de "alumnas internas". $\mathrm{Al}$ respecto en el reglamento de las religiosas de la Santa Cruz en Loncoche encontramos el siguiente detalle respecto a lo que debían portar las alumnas:

Un colchón de un metro de largo y 80 centímetros de ancho, una almohada y un almohadón, tres frazadas de lana, dos colchas blancas, cuatro sábanas, cuatro fundas de almohada, una alfombrilla de cama, tres camisas de dormir, cuatro camisas, cuatro calzones, cuatro corpiños, cuatro paños de mano, cuatro pañitos para el aseo del lavatorio, cuatro servilletas, 12 pañuelos, dos delantales blancos sin mangas, dos delantales negros de canesú con mangas largas, cinturón bolsillo, cuello blanco sobrepuesto según modelo del colegio, enaguas y refajos entre ellos, seis pares de medias, dos pares de zapatos, dos bolsas para la ropa, un paragua, un cubierto grabado, un vaso, escobilla de dientes, uña, ropa y zapatos; un peine, una peineta, un jabón, una jabonera, una bacinica, un betún para los zapatos, una caja de costura, un velo negro, un par de guantes negros y un par de guantes blancos, dos vestidos de color para el diario y un abrigo para el invierno. (Religiosas Maestras de la Santa Cruz de Menzingen, 1912, p. 9)

Las alumnas externas se distinguían de las alumnas internas por el uso de una boina azul, la que al centro tenía bordada la insignia del colegio y un número que permitía a las religiosas saber a quién pertenecía la boina. En 1893 asumió en la orden franciscana como Prefecto de Misiones el R.P. Felipe Bórquez, quien fundó la misión de Carahue. Fue un gran colaborador de la Hermanas Terciaria. Consiguió del gobierno de Chile aumento de las subvenciones para el número de alumnas internas, a quienes tenían que mantener y vestir anualmente, así se visualiza en la Tabla 1.

Esta tabla contempla alumnas cuya edad fluctúa entre 10 y 14 años. De acuerdo a datos encontrados en el primer Censo realizado en Chile (1907) en el rango 10 a 11 años el total de población infantil femenina en 1907 era de 1433 niñas, de las cuales 506 sabían leer y 927 no sabían leer. En el rango 12 a 14 años el total de la población infantil femenina era de 1979 alumnas, de las cuales 723 sabían leer y 1256 no sabía leer. Estos datos permiten visualizar la importancia que tuvieron las escuelas misionales internados que se instalaron en la Araucanía, específicamente en la provincia de Cautín. No existen datos oficiales que permitan cuantificar a la población infantil mapuche (Comisión Central del Censo, 1907, p. 1080).

Por su parte, los alumnos internos eran educados principalmente por los Padres Capuchinos bávaros, quienes compartían durante el transcurso de todo el día con los estudiantes y visualizaban a aquellos niños y jóvenes que podrían ser reclutados para ser misioneros y transformarse en sacerdotes, lo que facilitaba el proceso de evangelización de los mapuche. 
En este periodo se inicia una segmentación que se transformará en estructural en la Araucanía, ya que entre 1887 y 1915 se crearon en esta región al menos 19 colegios vinculados con familias de inmigrantes europeos que se instalaron en la Araucanía. 12 de estos colegios estuvieron relacionados con la comunidad alemana, uno con suizos, cinco con la comunidad francesa y uno con ingleses. Estos últimos identificados con la religión protestante (Zavala Cepeda, 2008) (Figuras 4 y 5).

En Chile, la primera estrategia para internar niños se materializó con la creación de escuelas para los hijos de la alta jerarquía indígena en 1774, en el periodo colonial. Los estudiantes para matricularse debían pertenecer al grupo dirigente de los mapuches (Lira, 1977). En este contexto la separación pedagógica por género se visualiza en la siguiente textualidad extraída desde un nütram:

(....) las niñas y los niños estaban por acá por otro lado, ellos eran más libres, tenían el patio libre pero nosotros las niñas estábamos como encerradas en un... como en un espacio cerradito con mallas y ahí a veces nosotros nos subíamos arriba de los cercos de las mallas y mirábamos por allá donde estaban

Tabla 1 - Evolución de matrícula y condición de alumnas mapuche en la Provincia de Cautín 1889-1907.

\begin{tabular}{l|c|c|c|c}
\hline Año & Condición & $\mathrm{N}^{\circ}$ matriculas & Condición & $\mathrm{N}^{\circ}$ \\
\hline 1889 & Indígenas internas & 14 & Pensionadas internas y externas & 0 \\
\hline 1890 & Indígenas internas & 25 & Pensionadas internas y externas & 26 \\
\hline 1891 & Indígenas internas & 43 & Pensionadas internas y externas & 45 \\
\hline 1892 & Indígenas internas & 55 & Pensionadas internas y externas & 35 \\
\hline 1893 & Indígenas internas & 58 & Pensionadas internas y externas & 31 \\
\hline 1894 & Indígenas internas & 60 & Pensionadas internas y externas & 43 \\
\hline 1895 & Indígenas internas & 62 & Pensionadas internas y externas & 40 \\
\hline 1896 & Indígenas internas & 80 & Pensionadas internas y externas & 57 \\
\hline 1897 & Indígenas internas & 75 & Pensionadas internas y externas & 49 \\
\hline 1898 & Indígenas internas & 100 & Pensionadas internas y externas & 35 \\
\hline 1899 & Indígenas internas & 103 & Pensionadas internas y externas & 42 \\
\hline 1900 & Indígenas internas & 102 & Pensionadas internas y externas & 40 \\
\hline 1901 & Indígenas internas & 95 & Pensionadas internas y externas & 23 \\
\hline 1902 & Indígenas internas & 94 & Pensionadas internas y externas & 44 \\
\hline 1903 & Indígenas internas & 103 & Pensionadas internas y externas & 40 \\
\hline 1904 & Indígenas internas & 100 & Pensionadas internas y externas & 35 \\
\hline 1905 & Indígenas internas & 98 & Pensionadas internas y externas & 45 \\
\hline 1906 & Indígenas internas & 105 & Pensionadas internas y externas & 58 \\
\hline 1907 & Indígenas internas & 125 & Pensionadas internas y externas & 25 \\
\hline
\end{tabular}

Fuente: Mansilla, 1905. 


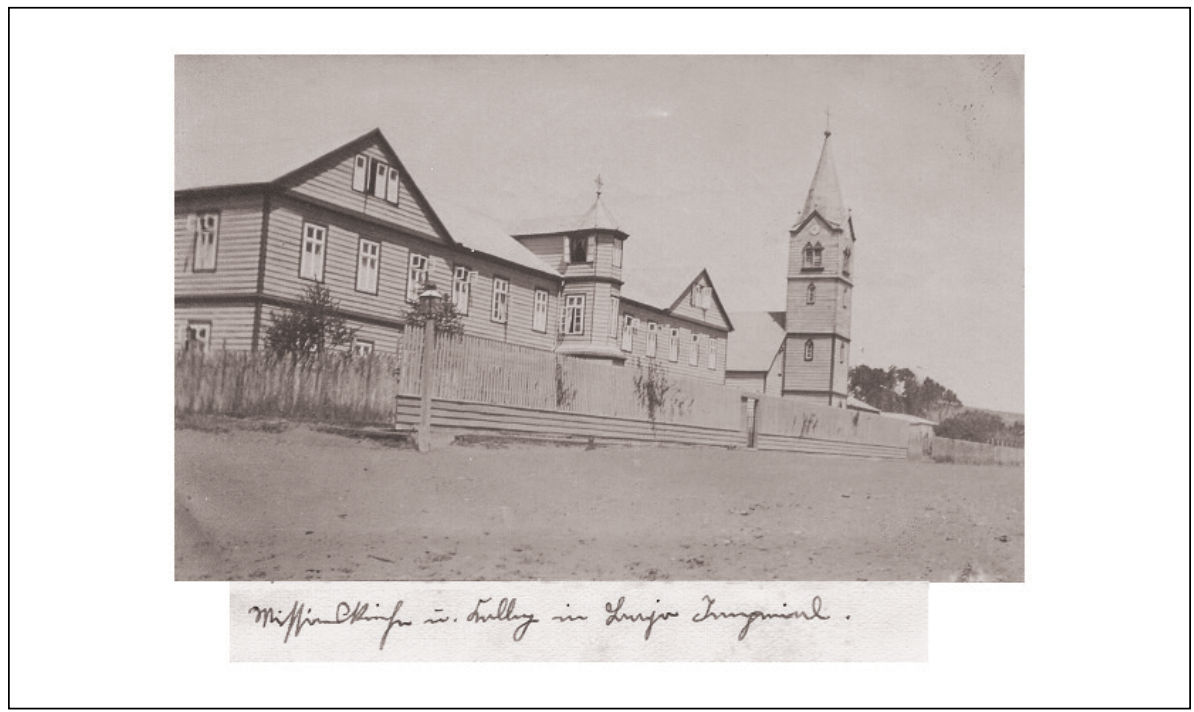

Figura 4 - Kolleg von Panguipulli. Colegio misión-internado, Panguipulli, 1907.

Fuente: Álbum 4. Imag. 386. Archivo Capuchino de Altötting (Archiv Der Bayer-Kapuzinerprovinz, Universitat EichstaettIngolstadt, 1907).

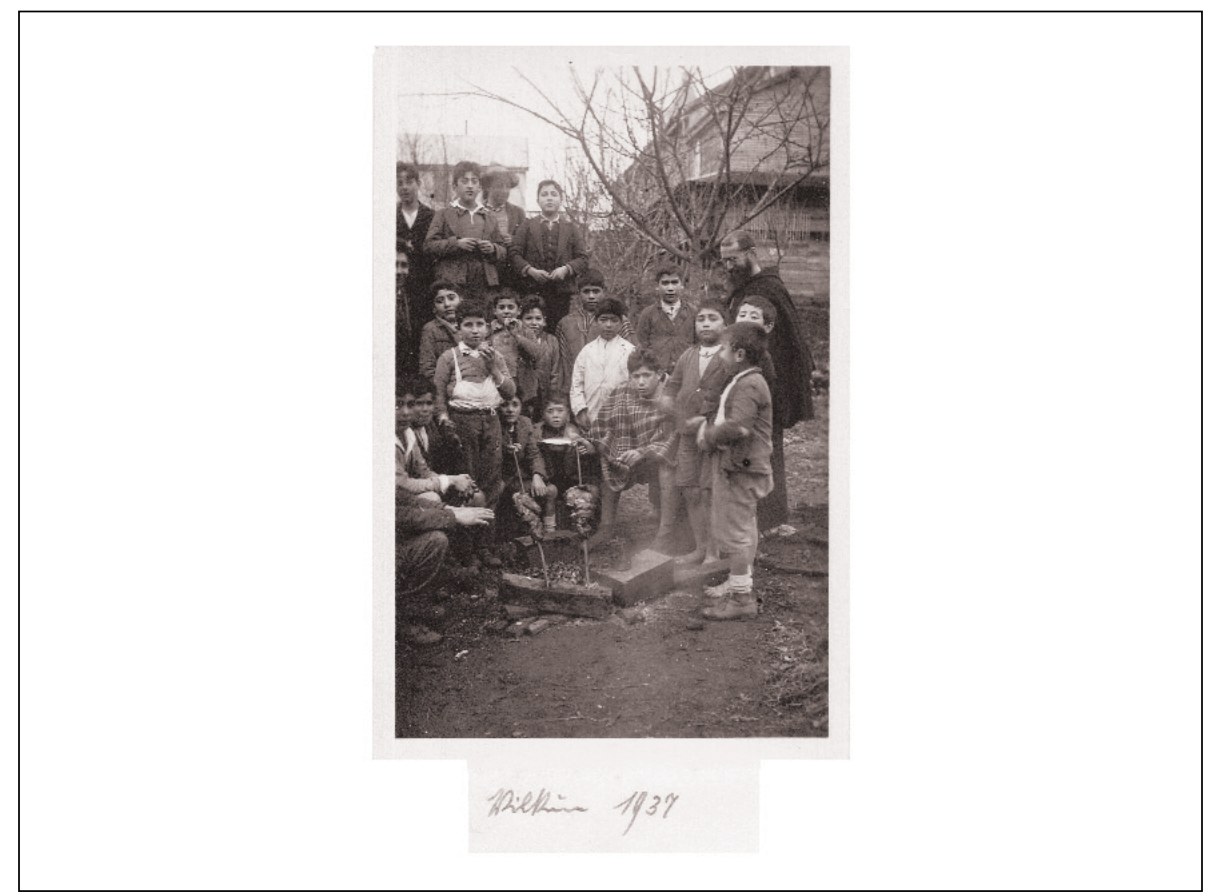

Figura 5 - Schulbuben des Internats von Vilcun, 1927. Niños escolares del internado de Vilcún, 1927.

Fuente: Álbum 13. Imag. 654. Archivo Capuchino de Altötting (Archiv Der Bayer-Kapuzinerprovinz, Universitat EichstaettIngolstadt, 1927). 
los chiquillos, los hombres... y en las clases también estaban las puras mujeres aquí en los bancos y este lado los hombres, separaditos. (Canío y Canío, 2016)

Posteriormente, las religiosas de la Providencia instalarían un "asilo" (internado) para hijos de caciques a principios del siglo XX en Temuco. Según Noggler (1972) se establecían 15 días de internado para los mapuches catecúmenos, confirmandos o novios, y otros 8 días para completar el proceso formativo. Con estas ideas en mente, los Capuchinos Bávaros hicieron su aparición fijando una serie de normas para enfrentar la evangelización teniendo como depositarios a los jóvenes mapuche, utilizando la modalidad educativa de instrucción. Para ello, los Bávaros llegaban a las familias mapuches y conquistaban a sus hijos para ingresar a la educación instructiva.

\section{CATEGORÍA 3. INFANCIA MAPUCHE REGLAMENTADA: FORMALIZACIÓN DE RUTINAS}

En todas las misiones con internado se cultivaba la comunión diaria de los niños, se celebraba la congregación mariana, la cruzada eucarística, y la cofradía del Carmen y todas las fiestas del calendario litúrgico. Una de las principales dificultades que tenía la población para acceder de modo expedito a la escuela eran las distancias y la baja calidad de los caminos. Se fundaron internados para ambos sexos. Los internados de mujeres eran atendidos por la Congregación de las Hermanas Maestras de la Santa Cruz y los internados para hombres eran atendidos por los misioneros capuchinos bávaros:

En 1935 existía en el territorio del Vicariato 24 internados: 12 para hombres y 12 para 24 mujeres: 12 para hombres y 12 para mujeres, y son los siguientes: Boroa, Cunco, Padre Las Casas, Panguipulli, Puerto Saavedra, Purulón, Quilacahuín, San José, San Juan de la Costa, Vilcún, Villarrica y Toltén. (De Frauenhäusl, 1912, p. 14)

En estos internados se educaban anualmente un promedio de 2.000 niños. A cada internado está agregado un externado para aquellos estudiantes que vivían cerca de la misión. La enseñanza era completamente gratuita. Para la pensión contribuían algunos padres de familia con una escueta cuota de dinero, o víveres, consistentes en trigo, papas y arvejas. Asimismo, en los internados se implementó los "lunes cívicos" con el objetivo de chilenizar a los niños. Muy temprano antes de ir a la escuela los inspectores desarrollaban sintéticos temas que versaban sobre deberes y obligaciones de los ciudadanos para con la Nación; sobre las virtudes que deben adornar a los hombres de bien; y sobre la moral, urbanidad y reglas de buena crianza (El Diario Austral, 1921, p. 12). A continuación presentamos propaganda de evangelización y chilenización que está a la base de la instalación de la escuela misional e internados (Figura 6).

Así se describía en las crónicas de la misión Purulón el Padre Sigisfredo los internados en 1926: "Son faros luminosos erigidos y sostenidos a veces con los mayores sacrificios, junto a los pies de los volcanes Llaima y Villarrica, temibles por sus continuas erupciones, a las orillas encantadoras de los lagos Caburga, Villarrica, 
Calafquén, Panguipulli, Riñihue,y Ranco, en los románticos valles de Lonquimay, de Allipén y Llaima, en las oscuras selvas vírgenes de Collico, de Carén y Coñaripe" (Archivo Obispado de Villarrica, 1926, p. 75).

Esta descripción subraya el sacrificio realizado por los misioneros, ya que, llevar a cabo una misión cerca de un volcán era vivir en un ambiente complejo, peligroso y salvaje. A la vez, el énfasis en la descripción de la naturaleza (salvaje) virgen, evidencia la necesidad de "estar ahî" para evangelizar, civilizar y chilenizar, especialmente a los mapuche. Más adelante el Padre Sigisfredo será más explícito cuando escribe - con el objetivo de solicitar apoyo económico de la comunidad local e internacional. Lo anterior se refleja en el siguiente texto:

Un ejército de profesores seglares nos acompaña en esta tarea (a los capuchinos) en la dura tarea de educar a miles de niños, a veces, medio salvajes. Compadeceos de nosotros y enviad vuestras limosnas para que no se derrumbe esta obra colosal de educación. (Archivo Obispado de Villarrica, 1926, p. 213)

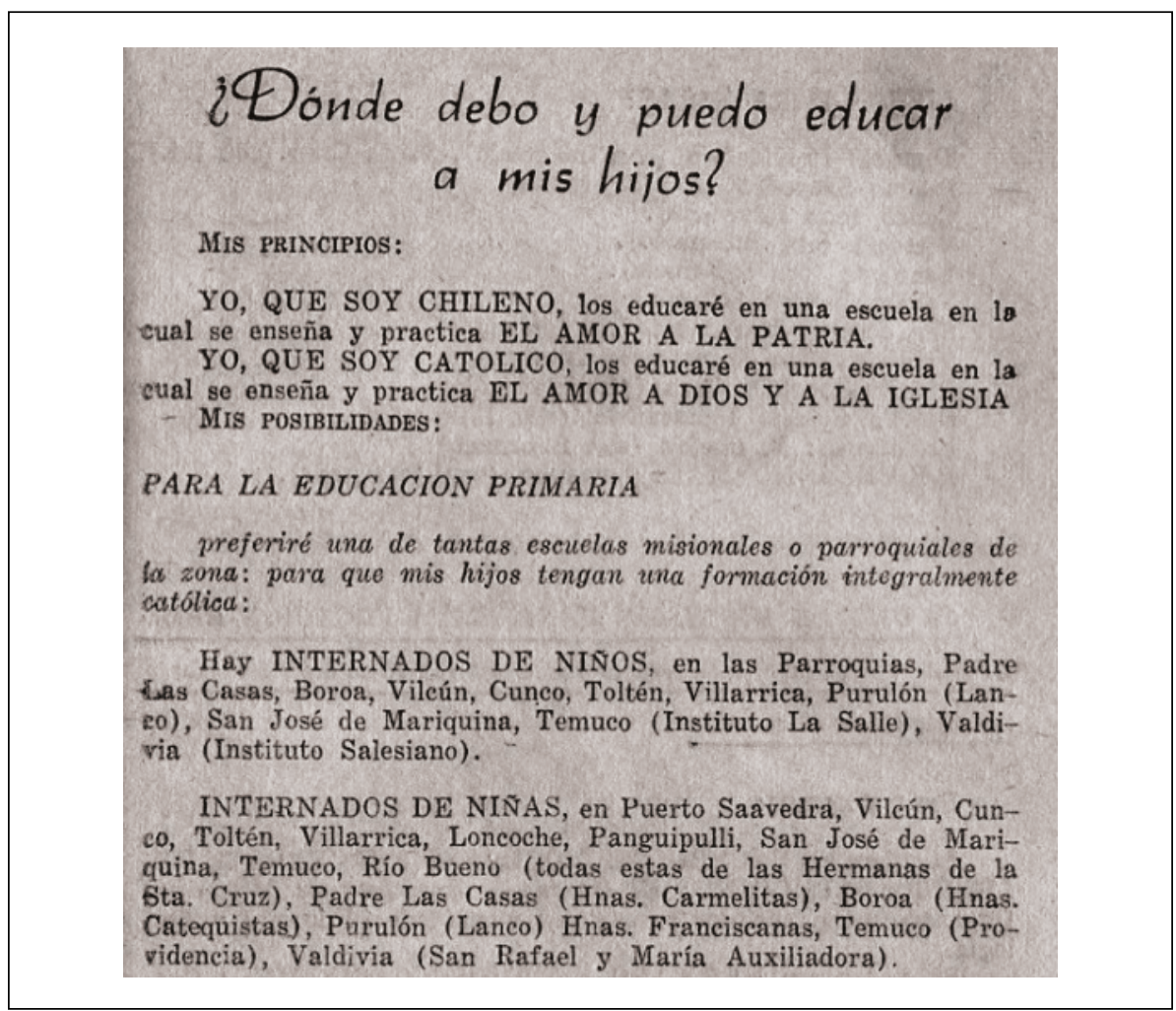

Figura 6 - Propaganda para chilenizar y evangelizar a niños y niñas de la Araucanía.

Fuente: Vicariato Apostólico de la Araucanía, 1930. 
En los internados capuchinos, la vida estaba reglamentada y poseía un orden estricto que disponía horas específicas para la realización de cada actividad. En la siguiente tabla se aprecia el horario, confeccionado por los misioneros bávaros, que regía la vida de los alumnos del internado de Padre Las Casas, que se mantuvo vigente sin sufrir modificaciones por dos décadas (Ferrando, 1986). La jornada completa para los alumnos internos constaba de 14 horas, comenzando a las 6 am $\mathrm{y}$ terminando a las $8 \mathrm{pm}$. Para las clases dentro del aula estaban destinadas 6,5 horas diarias. Los trabajos manuales ocupaban casi dos horas al día y las actividades de doctrina religiosa incluían misa matutina diaria, rezo de rosario a media tarde y oración personal antes del descanso nocturno (Tabla 2).

Los misioneros capuchinos bávaros sugerían para el desayuno café con leche. La principal comida era el almuerzo, preferentemente carne, pescados y derivados de harina. La once debía incluir té, pan con mantequilla, huevos y jamón. No debe haber cena, a lo más, un vaso de leche con pan "remojado" para los que estaban

Tabla 2 - Rutina de estudiantes del internado capuchino de Padre Las Casas, 1925.

\begin{tabular}{c|c}
\hline Hora & Actividades \\
\hline $6: 00$ & Levantarse, lavarse, arreglar las camas \\
\hline $6: 30$ & $\begin{array}{c}\text { Santa Misa, en la cual dos veces por semana se rezará el rosario, } \\
\text { dos veces se cantará i dos veces se leerán las oraciones de la Misa }\end{array}$ \\
\hline $7: 00$ & $\begin{array}{c}\text { Aseo del dormitorio, de la escalera, del pasadizo, del salón, del laboratorio i } \\
\text { del lugar. Los que no tienen trabajos de aseo, estudiarán en sus respectivas salas }\end{array}$ \\
\hline $7: 30$ & $\begin{array}{c}\text { Desayuno (café y pan alterando con cheican -sopa de } \\
\text { harina tostada-), aseo del comedor i de los útiles de comer }\end{array}$ \\
\hline $8: 00$ & Recreo \\
\hline $8: 30$ & Clases \\
\hline $11: 30$ & Recreo \\
\hline $11: 45$ & Almuerzo (alternando porotos, arroz, arvejas, pantrucas, papas, habas \\
\hline $12: 30$ & i los domingos i fiestas, carne), aseo del comedor i de los útiles de come \\
\hline $13: 30$ & Recreo \\
\hline $15: 00$ & Clases \\
\hline $15: 15$ & Recreo \\
\hline $15: 45$ & Once (harina tostada), aseo del comedor i de los útiles del comedor \\
\hline $17: 30$ & Almuerzo (alternando porotos, arroz, arvejas, pantrucas, papas, habas de la noche y acostarse \\
\hline $18: 00$ & Recreo \\
\hline $19: 00$ & Estudio \\
\hline $19: 15$ & Rosario \\
\hline
\end{tabular}

Fuente: Vicariato Apostólico de la Araucanía, 1925. 
“más flacos”. Los castigos de alimentos no se debían aplicar jamás sobre las comidas fundamentales, sino sobre los postres y golosinas (Barros-Arana, 1904).

En este mismo orden de cosas, la imposición de hábitos de higiene formaba parte de un sistema que buscaba modernizar y civilizar el espacio escolar. Por consiguiente, el ordenamiento del tiempo y espacio al interior del internado estuvo al servicio de normalizar la práctica escolar. Respecto a la higiene corporal, los niños debían bañarse por lo menos una vez a la semana durante la primavera, verano y otoño; y cada 14 días en invierno. Por otra parte, la cocina de los internados debía ser un modelo de aseo escrupuloso, tanto para las enfermedades que desde ahí se desarrollaban, como por la necesidad de convencer al niño y niña que la cocina es el departamento más importante de cada casa (Barros-Arana, 1904).

Entrevistas realizadas a personas mapuches que vivieron la escolarización del internado plantean que eran espacios de vigilancia y castigo, tal como se evidencia en el siguiente relato:

(...) en el internado nos daban desayuno en la mañana, (...) uno se despertaba en la mañana, nos decía: jarriba a lavarse todo y primero antes de bajarse de la cama a rezar! y ahí iban a lavarse todo... después el desayuno, y nos daban tarea... tareas, o sea, limpiar la sala, la sala de las monjas, limpiar la cocina, toda la casa, una aseaba el corredor y otra una salita y otra la cocina, otro grupo iba hacer el pan, otro grupo iba a buscar la leña, bueno en la leña a veces íbamos todos, antes de clases teníamos que ir todos a buscar leña, íbamos a la leñera, todos llevábamos leña a la cocina y ahí el pan se cocinaba con la leña y nosotros traíamos leña, corriendo pasábamos por el corredor y en una de esas doblo corriendo y mi otra compañera iba atrasito y yo doblo y viene una monja por la cocina "por aquí" (...) viene justo por donde estoy y yo doblo y choqué con ella y se me cae la leña y le pegue en los pies con la leña, cayó encima de su pies, y la monja se enojó tanto que pesca un palo que yo llevaba y con el mismo palo me dio. (Canío y Canío, 2016)

Las condiciones de los dormitorios se orientaron desde el modelo alemán bávaro (Figura 7). Debían tener pisos de aseo fácil, lo mismo que los muros, ventanas anchas, las que debían extenderse hasta cerca del cielo de la pieza; la ventilación debía ser "amplísima”, manteniendo durante todo el día abiertas las puertas $\mathrm{y}$ ventanas, $\mathrm{y}$ en la noche ventilación artificial. Los lavatorios y roperos estaban fuera de los dormitorios, al igual que las bacinicas. La temperatura del dormitorio debía tener un promedio de $12^{\circ}$ Celsius. Las ropas de cama se mudaban una vez por semana y se ventilaban diariamente. Existía una enfermería, en un pabellón separado con una o dos camas aislables para enfermos graves o contagiosos, quienes eran visitados por el médico escolar cuando la situación de salud lo requería (Barros-Arana, 1904).

Respecto a la presencia capuchina en educación primaria los datos que a continuación exponemos muestran la evolución de las escuelas y número de matrículas entre 1900 y 1940 en el territorio eclesiástico del Vicariato Apostólico de la Araucanía (Tabla 3). 


\section{CATEGORÍA 4. VISITAS CONTROLADAS A LOS INTERNADOS DE PARTE DE LAS FAMILIAS}

Las alumnas podían ser visitadas por sus padres o apoderados todos los domingos y días festivos de $11 \mathrm{Am}$ y $4 \mathrm{PM}$, exceptuando el tiempo reservado para el almuerzo, 11.45 a 12.30). Sin causa especial no era permitido realizar visitas extraordinarias. A las alumnas internas se les concedía salir el primer domingo de cada mes, siempre y cuando sean los padres quienes las retiren. Se excluía del permiso de salida "a aquellas alumnas a las que se les haya observado mala conducta, o hubieran sido desaplicadas en sus estudios. En septiembre tenían derecho a un asueto de diez días" (Archivo Obispado de Villarrica, 1926, p. 11-12).

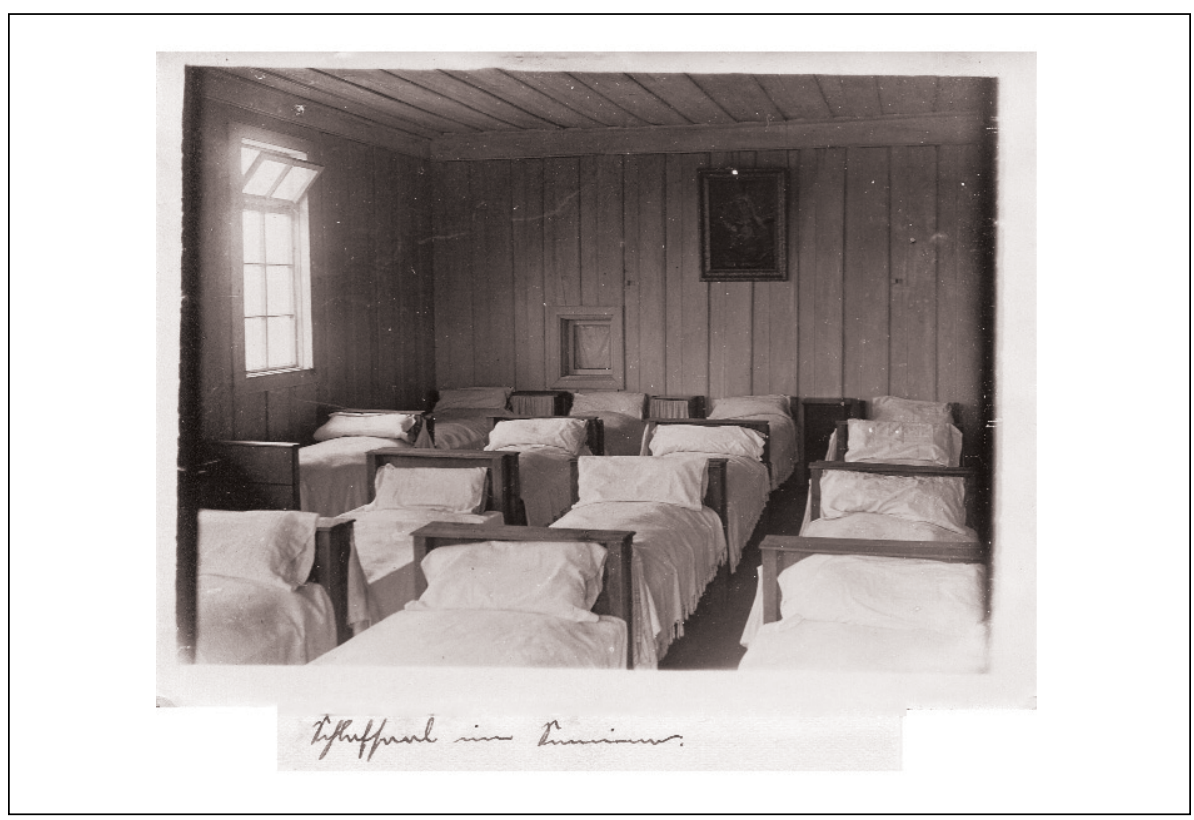

Figura 7 - Schlafsaal im Indianerkolleg Internats". Dormitorio en el colegio internado de indios, 1910, Bajo Imperial. Fuente: Álbum 13.Imag. 654. Archivo Capuchino de Altötting (Archiv Der Bayer-Kapuzinerprovinz, Universitat EichstaettIngolstadt, 1910).

Tabla 3 - Evolución de la matrícula de escuelas e internados a cargo de los misioneros capuchinos bávaros en la Araucanía: 1900-1930.

\begin{tabular}{l|c|c|c}
\hline Años & $\mathbf{N}^{0}$ de escuelas & $\mathbf{N}^{0}$ de internados & Matrícula \\
\hline 1900 & 6 & 3 & 300 \\
\hline 1910 & 16 & 5 & 1800 \\
\hline 1920 & 24 & 12 & 2750 \\
\hline 1930 & 63 & 15 & 5100 \\
\hline
\end{tabular}

Fuente: Archiv der Bayer-Kapuzinerprovinz, Universitat Eichstaett-Ingolstadt, 1974. 


\section{CATEGORÍA 5. JUSTIFICACIÓN IDEOLÓGICA DE LA PRESENCIA DEL INTERNADO}

$\mathrm{El}$ internado aparece como la institución más eficiente para lograr la conquista de las almas de los niños y niñas, para así completar el proceso de conquista que se materializó con la pérdida de las tierras ancestrales mapuches después de 1883. En los internados se podían controlar los diferentes mundos de la vida de los niños, para que de este modo ellos y ellas logren el convencimiento que la cultura occidental, chilena y europea era superior y se constituía en el horizonte-utopía hacia donde debían caminar. Así como los misioneros franciscanos realizaban "correrías" tierra adentro, los jesuitas efectuaron la fracasada guerra defensiva, los misioneros capuchinos practicaron a comienzos del siglo XX visitas pastorales sistemáticas al interior de las comunidades mapuches con el objetivo de convencer a los longkos de la importancia del envío a sus hijos a la escuela misión. En este contexto, el Padre Guido Beck de Ramberga visitaba las diversas reducciones indígenas ultra Cautín, ganando en cada una, a un amigo especial que con gusto ponía su casa a disposición para las funciones de culto. Al mismo tiempo, invitaba a los padres a que los niños vivan la experiencia del "pequeño internado", el cual albergaba entre 15 y 20 infantes, el cual también tenía una escuela para externos, en 1935 (Vicariato Apostólico de la Araucanía, 1930). Un ejemplo paradigmático del éxito de la misión capuchina en territorio mapuche fue la formación del indígena mapuche Pascual Alcapán, quien en 1918 quedó a cargo del internado siendo un joven indígena, formado en la misión de Panguipulli. Era un muchacho muy formal, que recibía diariamente la primera comunión, dando con ello un excelente ejemplo para los demás alumnos mapuches. Fue el primer sacerdote mapuche en ordenarse al amparo de la congregación capuchina bávara.

\section{CATEGORÍA 6. PÉRDIDA DEL IDIOMA MAPUNZUGUN Y ALTERACIÓN DEL MOGEN}

La imposición del idioma castellano sobre el idioma mapuzungun a través de las escuelas misionales a principios del siglo XX implicó la gradual destrucción del ethos configurador del niño y niña mapuche. Esto significa que se deshace la co-pertenencia entre lenguaje y el mundo, en tanto mundo de la vida auténtico (lebenswelt), ya que éste existía como analogía de la naturaleza, y que surge a partir del Az-mapu (modelo construido desde el mapun kimün: conocimiento mapuche); y esto significaría que las palabras y las cosas se separan en pro del funcionamiento de una representación que se guía ya no por imitación, sino justamente por la expresión de un determinado juicio del sujeto que se establece desde los conceptos de una lógica universal (Foucault, 2008).

La lengua es un medio troncal en las expresiones del pensamiento, en sus diversos niveles de profundidad y complejidad, y contiene por una parte, el ordenamiento conceptual que da cuenta del entramado del proceso de construcción de conocimiento, así como la diversidad de conceptos sobre el mundo natural, social, cultural, y cosmovisional-espiritual.

El mogen es un concepto mapuche que debe entenderse como mundo de la vida o tener/poseer vida, es una noción maestra mapuche que refiere a diversos niveles de la vida y de estar con vida, estar sano, lo que implica los planos de la 
salud, el sustento - mogelün -, estar el relación con los demás. Por otro lado, refiere también a existencia, o condiciones para la vida, como se expresa en "Pelan ñi mogeaqel faw, pelan küzaw" (Augusta, 1903. p. 56).

\section{CATEGORÍA 7. AGENTES DE LA VIGILANCIA Y EL CONTROL}

El agente principal de un internado es el inspector o inspectora. Es el encargado de la vigilancia, la cual debe ejercer constantemente. En el Congreso General de Enseñanza Pública se especifica lo siguiente: "es menester que el inspector adquiera el parecido del cuidado paterno, que vigila sin mortificar, para que el niño se sienta cuidado y querido, para que tenga la confianza de pedir consejos y la seguridad que se le den buenas recomendaciones de hábitos. La influencia de un inspector de internos sobre el carácter del niño es considerable; la bondad, firmeza y justicia deben formar la base de su carácter y el número de niños confiados al cuidado de cada inspector debe ser reducido, para que su acción sea eficaz y pueda estudiar el carácter de cada uno y tratarlo en consecuencia”. (Barros-Arana, 1904, p. 573). El inspector debe vivir en el establecimiento, comer en la mesa de los niños, acompañarlos en sus juegos. La situación ideal es que el inspector del internado sea profesor para que la enseñanza sea continua y la corrección inmediata (Barros-Arana, 1904, p. 574). Otros agentes importantes que asistían regularmente a los internados misionales fueron: los visitadores de escuelas, profesores, médicos escolares, directores de escuela e inspectores escolares.

\section{DISCUSIÓN}

Hoy son escasos los libros de historia de la educación que nos muestran a los mapuches en internados o en escuelas misionales en pleno proceso reducción a fines del siglo XIX y comienzos del siglo XX. Se plantea la idea que finalmente los mapuches aceptaron el concepto de una "escuela internacional" y cristiana, indistintamente si esta era católica o anglicana, en la medida que les ofrecía "transferencia tecnológica”, es decir, desarrollo de actividades industriales, maquinación agrícola, y socialización de herramientas de reproducción ideológica (alfabeto, imprenta, fotografía) concebidas éstas como conjunto de transformaciones que en aquel tiempo, en clave de darwinismo social, se denominó "civilización" y que los mapuches aceptaban de buen grado siempre y así los "civilizadores" se fueron haciendo cargo de la mantención de sus hijos en un régimen de internado (Menard y Pavez, 2007, p. 12).

El currículo de estudio que ofrece la escuela de modo formal y explícito se complementó con el currículo que ofrece el internado: apicultura, huerto escolar, herrería, zapatería, horticultura, costura y bordado, economía doméstica, diferenciando claramente los roles de género, generándose en consecuencia, el disciplinamiento de los cuerpos y almas mapuches.

Las fotografías muestran una transición de un "sujeto salvaje" que camina a un estadio "civilizado", coexistiendo ambas condiciones. El lenguaje discursivo de las fotografías evidencia la construcción de una imagen primitivista y exotista 
del mapuche, en ese momento bajo la etiqueta "indio/a" o "araucano/a". La acción que pretende el fotógrafo es adelantar el rito fúnebre y acostumbrar al público a la idea de la desaparición. Fenomenológicamente es un acto noemático de la imagen fotográfica que recrea la siguiente idea "esto es y está siendo lo que ha sido para ser otra cosa que es lo que soy yo", dicho de otro modo, "la certeza de una catástrofe que ya ha tenido lugar". Reducción de los cuerpos sumergidos en el espacio del internado a partir de una pose que esconde la derrota del indígena e inaugura una nueva colonialidad a partir de uno de los dispositivos más sutiles, eficaces y queridos: el internado.

Los internados desvistieron y revistieron a los niños y niñas. La congregación de las religiosas de la Santa Cruz, Hermanas de la Providencia, y Hermanas franciscanas provenían de un orden burgués, por tanto, portadoras de "otro modo de ser y estar en el mundo", situación similar ocurre con misioneros y misioneras anglicanos de la era victoriana decimonónica.

El internado es la concreción material de la implementación de la misiónescuela, a través de una organización curricular (secuenciación y temporalización del acto de la enseñanza) basado en la división social y sexual del trabajo. La tarea misionera de la escuela es dividir: internados para hombres mapuches e internados para mujeres mapuches con educadores del mismo sexo que los estudiantes, luego una vez formados en los valores burgueses y cristianos el internado permitirá que los educandos abandonen ciertas prácticas "primitivas" como la poligamia, uso de braseros y celebración de guillatunes para que así en el futuro se casen formando una familia nuclear, luego, - idealmente - los mejores estudiantes se convertirán en preceptores o misioneros, y volverán a la escuela o misión logrando la transformación social y la ansiada civilización. Este ciclo formativo encontró condiciones políticas y jurídicas favorables porque la Iglesia y el Estado en Chile no estaban separados.

El internado separó al niño y niña mapuche de su lof che (comunidad mapuche que vive de modo extenso). En este sentido es importante indicar que esta separación también involucró a otros agentes denominados "padrinos", situación que se originó en el siglo XVIII en la frontera del Biobío entre los mapuches e hispanocriollos wingka (no mapuches). Esta práctica se mantuvo en el periodo de la ocupación de la Araucanía y la instalación del Estado de Chile en territorio mapuche. Este padrinazgo consistía en vínculos de amistad entre los caciques mapuches y autoridades políticas, militares o misionales, en la que se entregaba a los hijos para ser alfabetizados en las "escuelas para los hijos de los caciques", quienes recibían una enseñanza especial, tal es el caso de la escuela para hijos de caciques en la ciudad de Temuco administrada por las religiosas de la Providencia.

Los internados fueron la estructura organizacional fundamental para lograr los objetivos de adoctrinamiento disciplinario y control social pensado desde la escuela y misión. Los estudiantes al permanecer internos disminuyeron sus posibilidades de ausentismo y deserción escolar, situación que se presentaba 
con más frecuencia en las temporadas agrícolas y ceremonias religiosas como el nguillatun ${ }^{5}$.

Los internados también se transformaron en un alivio para la economía doméstica de las familias mapuche porque en los internados podían comer todos los días. El pastor William Wilson de la escuela de Chol señala al respecto:

(...) si nuestro colegio ha tenido éxito, ha sido merced al internado gratuito, a los servicios médicos i la dispensaría, medios que nos han hecho adquirir su confianza [de los padres]. (Wilson, 1902 en Guevara, 1904, p. 79)

Los motivos de ingreso a los internados obedecían a diferentes situaciones, las cuales revestían el fondo del interés por el internamiento de parte de los misioneros: carencia económica en las comunidades (lof-che), la falta de alguno, o de ambos padres. Por tanto, se entremezclaban y confundían los objetivos de unos y otros: asistir, paliar, suplir; civilizar, evangelizar, disciplinar y normalizar.

En Temuco 1913 se desarrolló el VIII Congreso Científico Chileno, el cual fue realizado por la Sociedad Caupolicán. Hubo más de tres mil asistentes liderados por Manuel Nekulmán, Manuel Maquilef, Agustín Kolima, Domingo Paynefilu, Ambrosio Payllalef, Gerónimo Melillán, Juan Toribio Kidel, entro otros. En el discurso de agradecimiento el presidente del Congreso Científico y congresista radical, Ascanio Bascuñán Santa María prometió la "creación de un internado indígena en Temuco". La réplica no se hizo esperar, y se expresó en idioma mapuzungun como una advertencia a las futuras generaciones de la importancia de la lengua para la conservación de la propia cultura.

En este sentido, esta investigación permite complementar estudios que se han realizado en otros espacios de América Latina, tales como como Bolivia y México. En 1926 se creó la Casa del Estudiante Indígena y en 1932 los Centros de Educación Indígena en México. Para el caso boliviano se destacan las escuelas normales para indígenas de La Paz (1911 y 1931) y la escuela-ayllu de Warisata, en 1931. Al igual que en el caso chileno con las escuelas misionales capuchinas, los internados se instalaron en el campo (primitivo y atrasado) en tanto contexto natural de los indígenas (Giraudo, 2010). Si bien existen diferencias de finalidades respecto a la aparición de los internados, estos generaron efectos similares en la población originaria. Por ejemplo, en el caso de la Casa del Estudiante indígena, esta fue una orden directa del entonces presidente Plutarco Elías Calles, este internado se estableció en ciudad de México y congregó a jóvenes de 14 a 18 años, seleccionados y enviados por los gobernadores de sus respectivos estados entre los egresados de los dos primeros grados de la escuela rural (Dietz, 1999). Este fue un proceso de aculturación selectiva, en relación a una aculturación masiva, en el caso

5 Nguillatun: ceremonia de rogativa mapuche. Es un acto de petición que se realiza con intervalos de entre uno, dos, tres, o cuatro años, en un lugar sagrado especialmente dispuesto. La duración fluctúa entre dos y cuatro días, dependiendo de los territorios. El principal encargado de esta ceremonia es el ngenpin (dueño de la palabra) (Mora, 2016). 
de los internados capuchinos bávaros de la Araucanía. No obstante, en ambos casos, fueron dispositivos impulsados y agenciados desde el Estado.

\section{CONCLUSIONES Y PROSPECTIVA}

En este artículo hemos tratado de visibilizar un tema que se encuentra ausente en la investigación educativa en Latinoamérica respecto al rol que tuvo el internado como dispositivo de control cultural complementario a la escuela, misión, parlamentos y comercio, lo cual significó un complejo proceso de prestaciones culturales entre la cultura hispano-criolla-chilena y el pueblo mapuche.

Encontramos que los internados fueron un dispositivo de control social y cultural que volvió más eficiente el rol de la escuela en el proceso de constitución de los estados nacionales, sobre todo en Chile, donde los grupos dirigentes han pensado siempre la educación desde una dimensión centralista, elitista, unitaria y monocultural.

Los resultados de nuestro estudio plantean la necesidad de investigar y estudiar la historia de la educación en contextos locales sobre todo en realidades donde han existido prolongadas relaciones interétnicas para así comprender los actuales problemas y retos que enfrenta la educación intercultural no sólo en la región de la Araucanía y Chile, sino en América Latina, ya que una cantidad importante de las actuales tensiones hunden sus raíces en el pasado.

Los internados contribuyeron con su agenciamiento a la pérdida del idioma mapunzugun y se constituyeron en nueva frontera. En el campo formativo los niños y niñas mapuche perdieron la posibilidad de ejercitar la capacidad a desempeñar pepilpepiltun: ensayar, probar como parte del proceso de aprendizaje, en el sentido de si alguien puede o sabe hacer algo (Colipan, 2014). Lo anterior se fundamenta en que el idioma que se potenció en las escuelas, misiones e internados fue el español, y no el mapunzungun. A su vez las conversaciones en profundidad realizadas (nütram) permiten visualizar el desplazamiento del mapuzungun de la Araucanía, debido a que gradualmente las principales interacciones legitimadas desde la escuela, validaron el monolingüismo castellano e incluso castigaban físicamente el uso del idioma en algunos de los internados, principalmente en el espacio costero de la Araucanía (mapuches-lafkenches). Actualmente para las comunidades rurales indígenas mapuches se ha implementado El Programa de Educación Intercultural Bilingüe desde el Ministerio de Educación, con éxitos parciales. En los internados se difundió la lengua nacional que era la que se requería para desarrollar la vida cotidiana, social, política y económica, esto hizo que el castellano sea demandado. Este proceso se intensificó después de la incorporación forzosa de las comunidades mapuche al estado nacional chileno. No obstante, al bilingüismo castellano-mapunzugun es un hecho de larga data en las relaciones interculturales, que hunden sus raíces en el pasado colonial.

Las diferencias formativas de género aparecen como una dimensión de gran interés para comprender la ideología curricular que se operacionalizó en los contenidos pedagógicos que se enseñaron en escuelas y liceos de la Araucanía.

Queda abierta una nueva línea de investigación para Latinoamérica que permita comprender las compleja relación Estado-escuela-misión-internados y pueblos originarios. 


\section{REFERENCIAS}

Amunátegui, M.; Amunátegui, G. De la instrucción primaria en Chile: lo que es, lo que debe ser. Santiago: Imprenta del Ferrocarril, 1856.

Anderson, B. Comunidades imaginadas. Reflexiones sobre el origen y la difusión del nacionalismo. México, D.F.: Fondo de Cultura Económica, 1993.

Archiv Der Bayer-Kapuzinerprovinz, Universitat Eichstaett-Ingolstadt. Fotografía. Kolleg von Panguipulli. Colegio misión-internado, Panguipulli, 1907. . Fotografía. Schlafsaal im Indianerkolleg Internats. Bajo Imperial, 1910. . Fotografía. Colegio de niños de Boroa. Seite II, 1919. . Fotografía Schulbuben des Internats von Vilcun, 1927. . Matrícula de escuelas e internados en la Araucanía: 1900-1930,1974.

Archivo Obispado de Villarrica. Crónica de la misión San Antonio de Purulón, 1873-1952. Villarrica, 1999.

Augusta, F. Gramática Araucana. Valdivia: Imprenta Central, 1903.

Barros-Arana, D. Congreso general de enseñanza pública de 1902. Actas i trabajos. Tomo II. Secciones de enseñanza secundaria, superior, especial i práctica i de higiene, mobiliario y edificación escolar. Anexos. Santiago: Imprenta, litografía y encuadernación Barcelona, 1904.

Bourdieu, P. El sentido práctico. Buenos Aires: Siglo XXI Editores, 2007.

Bueno, A.B. Intervención social con menores. Alicante: Universidad de Alicante, 1996.

Canío, A.; Canío M. Nütram (entrevista oral) realizada a Lucinda Pichicona Gümay, mujer mapuche de 65 años, Comunidad Boroa-Filu Lawen. Duración: 1 hora y 12 minutos, oct., 2016.

Colipan, D.C. Desempeño del Profesor de Educación Intercultural Bilingüe: criterios evaluativos desde la voz del lof che. Polis, Santiago, v.13, n.39, p.1-19, ene. 2014.

Civera Cerecedo, A. El internado como familia: las escuelas normales rurales en la década de 1920. Revista Latinoamericana de Estudios Educativos (México), v. 36, n. 3-4, 3er-4to trimestre, oct.-dic. 2006.

Comisión Central del Censo. Memoria presentada el 28 de noviembre de 1907 al Supremo Gobierno de Chile. Santiago de Chile: Instituto Nacional de Estadísticas, 1907.

De Frauenhäusl, S. Resumen de las obras de civilización y cristianización de los padres capuchinos en la Araucania. Padre Las Casas: San Francisco, 1912.

De Pamplona, I. Historia de las misiones de los Padres Capuchinos en Chile y Argentina (1849-1911). Santiago: Imprenta Chile, 1911.

Diario Austral De Temuco. Labor de los inspectores en las escuelas de la Araucanía, p.12, 1921.

p. 12, 1931.

Las escuelas primarias de Cautín. Comentario del señor Esteban López, 
Dietz, G. La comunidad purhépecha es nuestra fuerza. Etnicidad, cultura y región en un movimiento indígena en Michoacán, México. Quito: Abya Yala, 1999.

Domínguez, F. Infancia en internados: historias, narrativas, itinerarios. Alicante: Universidad de Alicante, 2009.

Ferrada, D.; Villena, A.; Turra, O. Transformar la formación: las voces del profesorado. Santiago: RIL Editores /Editorial UCSC, 2015.

Ferrando, R. Y así nació la frontera. Santiago: Antártica, 1986.

FLICK, U. Introducción a la investigación cualitativa. Madrid: Morata, 2004.

Flores, J.F. Historia de la infancia en el Chile Republicano. Santiago: JUNJI, 2010.

Fondo de Intendencia de Cautín. Decreto n. 26. Archivo Regional de la Araucanía, Temuco, v. 47, p. 29, 1931.

Foucault, M. Las palabras y las cosas. Una arqueología de las ciencias humanas. 2. ed. Buenos Aires: Siglo Veintiuno, 2008.

Geertz, C. The interpretation of cultures. New York: Basic Books, 1973.

. Géneros confusos: la reconfiguración del pensamiento social. Barcelona: Gedisa, 2003.

Ghirardi, M.; Vassallo,J. El encierro femenino como práctica. Notas para el ejemplo de Córdoba, Argentina, en el contexto de Iberoamérica en los siglos XVIII y XIX. Revista de Historia Social y de mentalidades, Santiago, v.14, n. 2, p.73-101, 2010.

Ginzburg, C. Le juge et l'historien. Considerations en marge du procès Sofri. Paris: Verdier, 1997.

Giraudo, L. De la ciudad mestiza al campo indígena: internados indígenas en México posrevolucionario y en Bolivia. Anuario de estudios americanos, Sevilla, v. 67, n.2, 2010.

Goffman, E. Internados. Ensayos sobre la situación social de los enfermos mentales. Buenos Aires: Amorrortu Editores, 1972.

Góngora, M. Ensayo histórico sobre la noción de Estado en Chile en los siglos XIX y XX. Santiago: Ediciones de ciudad, 1981.

GonzÁlez, S. Chilenizando a Tunupa. La escuela pública en el Tarapacá andino (18801990). Santiago: DIBAM, 2002.

Guevara, T. Costumbres judiciales y enseñanza de los araucanos. Santiago: Imprenta Cervantes, 1904.

Gunckel, H. El muy reverendo Padre Atanasio Hollermayer, su vida y su obra. Revista Universitaria, v.30, n.1, p. 5-23, 1945.

Hartog, F. Evidencia de la historia. Lo que ven los historiadores. México, D.F.: Universidad Iberoamericana. Departamento de Historia, 2011.

Hoffmann, C.A.; Holzbauer, H.; Kramer, R. En la Araucanía. El padre Sigifredo de Frauenhäusl y el Parlamento mapuche de Coz Coz de 1907. Madrid: Iberoamericana; Frankfurt am Main: Vervuert, S.L, 2006.

Lira, L. Los reales colegios de Santiago de Chile: reseña histórica de los colegiales (1584-1816). Revista Estudios Históricos, n.21, p.2-18, mar. 1977. 
Mansilla, L. Las misiones franciscanas de la Araucanía. Costumbres araucanas, reminiscencias históricas y datos estadísticos relativos a la región en donde están ubicadas las misiones de la Prefectura apostólica de Angol. 1. ed. Padre Las Casas: San Francisco, 1905.

Menard, A.; PÁvez, J. Mapuche y anglicanos. Vestigios fotográficos de la Misión Araucana de Kepe, 1896-1908. Santiago: Ocho Libros Editores, 2007.

Muriá,J.; Olveda, J. Educación y cultura. Lecturas históricas de Guadalajara IV. 1. ed. México, D.F.: Instituto Nacional de Antropología e Historia, 1992.

Nizza da Silva, M. Familia y educación en el Brasil colonial, en Gonzalbo Aizpuru (comp.). Familia y educación en Iberoamérica. México D.F.: Colegio de México, 1999. p. 23-33.

Noggler, A. Cuatrocientos años de misión entre los araucanos. Padre Las Casas: San Francisco, 1972.

Palavicino, V. Memoria sobre la Araucanía, por un misionero del Colegio de Chillán. Santiago: Imprenta de la Opinión, 1860.

Mora, Z. Zungun: diccionario mapuche: palabras que brotan de la tierra. Santiago: Uqbar Ediciones, 2016.

Pinto Rodríguez, J. Frontera, misiones y misioneros. La Araucanía, 1600-1900. Temuco: Universidad dl La Frontera, 1988.

Pereira Contardo, K. El real colegio de naturales. Santiago: Publicaciones del Archivo Franciscano, 2002.

Religiosas Maestras de la Santa Cruz de Menzingen. Prospecto del Colegio Santa Cruz de Loncoche. Padre Las Casas: San Francisco, 1912.

Sepúlveda,J.M.; Llancavil, D.L.; Chacaltana, M.M.; Vargas, E.M. Instalación de la escuela monocultural en la Araucanía, 1883-1910: Dispositivos de Poder y Sociedad Mapuche. Revista Educação e Pesquisa, Sao Paulo, v.42, n.1, 213-228, mar. 2016.

Solana, F.; Reyes, R.C.; Martínez, R.B. Historia de la educación pública en México (1876-1976). México, D.F.: Fondo de Cultura Económica, 2014.

TAYLOR, S.J.; BogdAn, R. Introducción a los métodos cualitativos de investigación. Barcelona: Paidós, 1984.

Vicariato Apostólico de la Araucanía. Mi almanaque. Padre Las Casas: San Francisco, 1925. . Mi almanaque. Padre Las Casas: San Francisco, 1930. . Araucanía misional. Boletín del Vicariato. Villarrica, n. 62, 1-26, 1966.

Wilhelm de Moesbach, E. Voz de Arauco. Padre Las Casas: San Francisco, 1959.

Witt, L. Von Häuptlingen Zauberern und Glaubensboten im Araukanerland 1848-1890. Memorie inedite delle missioni del FF.MM. Cappuccini en Chili en Roma. Altötting: Verlag der bayerischen Kapuziner, 1963.

Zavala Cepeda,J.M. Los colonos y la escuela en la Araucanía: los inmigrantes europeos y el surgimiento de la educación privada laica y protestante en la región de la Araucanía (1887-1915). Universum, Talca, v. 23, n. 1, ene.-jul. 2008. 


\section{SOBRE LOS AUTORES}

Juan Guillermo Mansilla Sepúlveda es doctor en es doctor en Filosofía y Letras por la Universidad Pontifica de Salamanca. Profesor de la Universidad Católica de Temuco (Chile).

E-mail: juanumayor@gmail.com

Claudia Andrea Huaiquián Billeke es candidata a doctora en educación por la Universidad Academia de Humanismo Cristiano (Chile). Profesora de la Profesor de la Universidad Católica de Temuco (Chile). E-mail: chuaiquian@uct.cl

Gabriel Alfonso De Dios Pozo Menares es doctor en historia y antropología de América por la Universidad de Barcelona. Profesor de la Universidad Católica de Temuco (Chile).

E-mail: gpozo@uct.cl

Recibido el 18 de febrero de 2017

Aprobado el 11 de octubre de 2017 